\title{
Linguistic and Behaviour Interaction Analysis within Cognitive Infocommunications
}

\author{
Carl Vogel \\ Trinity Centre for Computing and Language Studies \\ Trinity College Dublin, the University of Dublin \\ Dublin, 2, Ireland \\ Email: vogel@tcd.ie
}

\author{
Anna Esposito \\ Università degli Studi della Campania Luigi Vanvitelli \\ Caserta, Italy \\ and \\ International Institute for Advanced Scientific Studies (IIASS) \\ Vietri sul Mare, Italy \\ Email: iiass.annaesp@tin.it
}

\begin{abstract}
Cognitive infocommunications is a discipline that examines the extensions of human cognitive capabilities that are assimilated within the concept of humanity. We argue that necessary (but not sufficient) conditions for the success of any candidate technology include solving problems within private and public spheres, in thought and communication. Exemplars such as emotion, gesture and language, as cognitive infocommunication technologies that have been assimilated, are examined. Implications for research programmes within cognitive infocommunications are addressed.
\end{abstract}

\section{INTRODUCTION}

Cognitive Infocommunications "coginfocom" as a discipline has been developing as an area of research scrutiny for over 10 years, with a successful series of annual academic conferences. To label the topic as a "discipline" suggests that there is some level of consensus among those who contribute to the area about what the primary problems are and how those problems overlap and decompose into constituent questions.

We find it to be a tenet of coginfocom that humans are prolific at extending their capabilities and assimilating those extensions into what is thought of as humanity. The development of clothing is an example: in addition to providing an infinitely re-configurable means of adornment and self expression, clothing also extends human potential for survival through a larger space of climate variations over what is feasible without clothing. The advantage of adaptability to climate variation operates at the individual level, privately, so to speak, while the expressive capacity of clothing is open to public view. ${ }^{1}$ Coginfocom gives attention to both the private and public dimensions of technologies that extend human capabilities. In the case of clothing, the extensions impinge upon, inter alia, possibilities for signalling group membership and status. The deployment of language as a system that supports communication as well as cogitation is another example of humans achieving innovations and assimilating them into their concepts of humanity. We argue that language demonstrates the canonical property of coginfocom technologies: affording advantages in both the private (as in thought) and public (as in communication) spheres of human behaviour.

\footnotetext{
${ }^{1}$ In contrast, tattoos provide a means of expression, but are not infinitely re-configurable; further, while they have clear public function, any private advantages that they confer are difficult to identify.
}

More recent technological advances also provide a source of examples, calculators, for instance, or telephony. In some cases, the innovations are established as nearly universally available, if not universally adopted. Vision-corrective eyewear is in this category, as is money.

Examples of technologies that appear to be candidates for assimilation but which are abandoned or subsumed by more general innovations also abound. Photographic slide projectors were seemingly popular for a time, but appear to have been abandoned without a functional replacement: while people continue to take photographs and take more than during the age of slide projection, the "event" of co-located sharing of enlarged images is no longer a social fixture among families. Personal time pieces, on the other hand, appear to have been largely incorporated into general purpose mobile devices that people keep with them, and technologies for replaying recorded music changes relatively frequently, but persist as a general function that many seek to maintain.

Each of the adopted extensions gives rise to academic disciplines, sub-disciplines, inter-disciplines that attempt to make sense of the fundamental principles of these extensions and how they impinge on individual activity and social interactions, including the development of societal structures. Coginfocom studies, among other issues, the principles that determine adoption or abandonment. Some seek to develop new candidate technologies; some seek to understand how humans behave with existing technologies. Behaviour, in this sense, refers to transitions among a range of psychological and physical states - manifestations of emotions, reasoning, interaction - and addresses states of the individual and of groups. Understanding how humans behave with existing technologies may identify "problems" that new technologies may solve, but new technologies are not the ultimate aim of all who pursue research well categorized within coginfocom. Rather, some hope to understand how extant technologies are used and adapted, and to grasp the principles that determine the difference between technologies that will become assimilated and those that gain only limited traction or none at all. For researchers in the latter category, understanding parameters of human thought and behaviour is essential.

One could imagine a paper in which, using a perspective such as just outlined, a research programme is specified, in the sense of articulating what the authors deem to be paramount 
questions that are not fully answered in relation to how humans use language and other systems in thought and in interaction. However, these questions may reduce to questions of cognate discipline: computer science, linguistics, logic, neuroscience, philosophy, psychology, sociology (and including engineering, as well, if the perspective of new technology development is taken). Indeed, works are available along those lines (e.g. [1]).

Our goal in this paper is to contribute views on what it takes for new technologies to become assimilated as part of humanity, in some cases to a degree that invokes epigenetics. We do this with reference to the thread of cogninfocom that addresses linguistic and behavioural interaction analysis. While one might think that the answer to the underlying question is trivial - that is, instances of successful coginfocom technologies (clothes, language, money, medicine, etc.) are good, but this is a problematic response for two reasons. Firstly, what "good" is has itself been an unresolved question at least since Plato recorded Socrates' asking of the question; secondly, on closer inspection, no instance of successful coginfocom technology is manifestly or persistently good. It could be, instead, that each instance is better thought of as an infection that has taken root in humanity and which, out of balance, could cause fatalities (in the manner of gut bacteria). ${ }^{2} \mathrm{We}$ work with a mixed view that each solves an actual or nearfuture problem, ${ }^{3}$ that the problems themselves change, and that the solutions habituate. Having a capacity to solve a problem is a selective advantage over lacking that capacity, and such capacities may be culturally propagated as part of habituation. Moreover, solutions to problems are frequently adapted to other purposes - that something has a contemporary function does not entail that it originated as a solution to the problem underlying that function, just as mobile phones were not invented to replace wrist-watches. In any case, the metaphorical field suggested by the word, "infection" is apt in that the innovations that are good enough to be assimilated by humanity do so through "contagion" - they "go viral".

\section{THOUGHT}

Artificial intelligence research has given significant recent attention to neural network models for unsupervised learning of input-output mappings in large quantities of data. In many applications within natural language technologies, systems based on such models achieve the best results available. While these network models may be successful in the sense of predicting expected responses to data outside their training data, there is not an evident tendency to ascribe thought to them (although there is a long history of analyzing thought as reducible to configurations of neurons and their electro-chemical behaviours). For many, "thought" involves, in addition, at least willful selection of input-output relations to monitor. Thought appears to have a useful function in guiding the macro-level time course of electro-chemical behaviours among connected neurons, and this seemingly solves the problem of otherwise arbitrarily structured consciousness, as in the logic of dreams.

Self-control of consciousness may be a species of free will, but it is separable from humanity. One who appears to be

\footnotetext{
${ }^{2}$ Of course, in balance, human gut bacteria provide for healthy coexistence.

${ }^{3}$ It seems that sometimes, innovations come along solving problems that people were not aware they had.
}

driven by a wholly predictable stimulus-response mechanism will still be regarded as human, and may, for example, be elected to the office of President of the United States. Within some jurisdictions, being a human lacking in self-control of consciousness is sufficient to trigger societal protections rather than the consequences of being deemed "not human" or "no longer human". The capacity for self-control of consciousness enables the perception of free will. It helps address the problems inherent in functioning in the "blooming, buzzing confusion" that people would otherwise experience. However, that it is not a universal good follows from the fact that many individuals prefer to yield control of their consciousness through the use of chemicals, music, meditation, etc.

\section{EMOTION}

As with thought, emotion is not a necessary component of humanity. However, perhaps more strongly than the case of lacking thought, lacking emotion can lead to an individual being labelled "inhuman" if not "not human".

\section{A. Thought}

Some may take the position that emotions are not chosen. It is, perhaps, easiest to make this case in relation to dimensions of disgust, possibly the most powerful of emotions, since disgust-triggers can be acquired from the aftermath of a single exposure to a particular toxin, and the disgust response is highly adapted in the sense of quickly transferring to associates of initial triggers, leading to irrational behaviours (e.g. someone may experience food poisoning from some particular meal, associate as triggers all variants of the meal, even with alternatives to the type of the ingredient that was rotten, and may decide never again to wear the outfit of clothes they were wearing at the time that the food poisoning resulted in vomiting, even if all physical traces of the event are effectively autoclaved away). However, some people are able to concentrate on aspects of their subsequent experience of disgust and intervene in the disgust response.

The desire to have or not have particular emotions is a useful guide in structuring thought and behaviour. One might wish to argue that shared aspects of embodiment force humans to have a common experience of emotions. However, it seems that this must be relativized to co-located embodiment, such as through shared culture and milieu, since, for example, disgust triggers are not universal. The disgust response (the oral-nasal reflexes associated with nausea and vomiting) evidently is universal. Thus, one might argue that the post-trigger and pre-intervention experience of disgust can be isolated as an emotion that is universally available (if not universally experienced) by virtue of aspects of embodiment shared by all humans. All the same, it may well be that the desire to experience particular emotions leads to self-direction of consciousness with focus upon how to obtain that emotion.

Having an emotion may be disruptive to aspects of thought. Reasoning is rational when it is guided by commitment to valid arguments and sensitivity to what cannot be concluded with logical validity. Where logical validity is not available, rational reasoning and decision making is influenced by probabilities. Emotions may easily cloud one's sense of what is likely. On the other hand, an emotion-led bias may provide the basis for 
decision where useful information is lacking, but decision remains necessary. In such cases, emotions may enable decision. This is not an argument that emotion-led decision making is logically valid - the benefits of emotion-led decision making do not extend to cases in which the decisions are at odds with valid arguments or more informative sources regarding probabilities, and applying emotion-led decision making beyond its circumscribed area of benefit can be disruptive.

\section{B. Communication}

Benefits may arise from it being known what one's emotions are. This holds within relationships of all sorts: couples, parent-child, siblings, within communities and among communities. The sorts of emotions people discuss determines the type of relationship that holds among them. The identification of which emotions are shared and which are not determines political discourse as much as it determines romantic discourse.

One of the marvels of the acting profession is that its members are able to convey emotions that they may not have (not every school of acting is like "method acting" in advising actors to project their own emotions onto the characters they portray). In general, humans "wear their heart upon their sleeves". It is when people attempt to hide their emotions that communication about emotions breaks down, because, in general, emotions declare themselves, and are merely decorated by any language used to express them. Further, many people report that language is insufficiently expressive to represent their emotions accurately and completely [2].

\section{LANGUAGE}

Language is a representation system humans use in thought and communication, but is not the sole medium for either.

\section{A. Thought}

The main function of natural languages appears to be thinking. People have more thoughts than they communicate, and they think the thoughts that they communicate. Human languages provide powerful features in support of nuanced thought, and among those features are those that are idealized in logical connectives "if" and "not". Humans are fully capable of thought that is not linguistic, including visualizing non-existing possibilities and potential developments of those possibilities. However, the most succinct way to describe a potential development within a non-existing possibility is as a "possible narrative": the word "narrative" expresses the linguistic representation of the unfolding of possibilities. Human languages allow representation of negation that is not supported by visual reasoning about positive possibilities. Conditionals also support representation of hypothetical or counter-factual situations. ${ }^{5}$ In addition to enabling people to distinguish between content that is not visualized and content that is not there to be visualized, between what is not known to be true and what is known to be false, natural language enables the representation of absolute impossibilities: for example, "this sentence is false" or "the set containing all sets is green". Representation is pre-requisite to reasoning.

\footnotetext{
${ }^{4}$ We apologize to Shakespeare; cf. Othello, Act 1 , Scene 1.

${ }^{5}$ Indeed, it is a move in formal logic to define negation using implication and impossibilities: where $\perp$ denotes logical inconsistency, $p \rightarrow \perp \equiv \neg p$.
}

\section{B. Communication}

Because people think in language, human language is also useful in communication, even though it is an imperfect code. People tend to know what they mean by what they say, but frequently have difficulty in understanding what others mean when using the same sentences. People do not use even formulaic expressions in uniformly the same manner as each other, and people frequently embark on linguistic innovations, for example, metaphor. Until telepathy is properly solved, humans have no way of knowing whether they have understood each other - at best, they may conclude that they lack evidence that they have misunderstood each other (and may make a representational leap by concluding that they have not misunderstood each other, and from their reason to a sense of mutual understanding). In the meantime, people use natural languages in communication as if they are successful, and when disagreements arise, sometimes embark on clarification to attempt to verify whether they are using language in different ways or actually have different positions.

\section{GeSTURE}

We take gestures to be bodily movements that accompany language. It follows that we see gesture as having a role in thought as well as in communication. It may be anticipated that we think the role of gesture in thought is more direct than in communication. In this section, we do not address bodily movements that constitute language, as in sign language. We think of sign language as language, and therefore with all of the limits and affordances described above ( $\mathrm{IV}$ ).

\section{A. Thought}

People gesture when they are alone. People are idiosyncratic in their use of gestures. We take these two facts to be self-evident, and sufficient proof of the argument that the purpose of gestures is not the communication of content. People use gestures in a manner that helps them focus their thoughts and represent them in language. It has been noted that people sometimes "hold" their gestures during utterance and thought repair [3]; this is evidence of the contribution of gesture to formulation of thought.

\section{B. Communication}

Some gestures are conventionalized in a manner that transcends idiolects, and many deictic gestures are in this category. Other gestures are created for the nonce, as iconic representations that work more or less well because of shared embodiment and shared perception of what is salient in a scene and how a bodily shape matches what is salient. Unconventional deictic gestures also exist, and also work through salience: if there is something noteworthy about a scene, doing something unusual with one's chin in the direction of the noteworthiness can be successfully understood as pointing toward the salient elements of the scene. However, this, too, requires the intention to point.

Much use of gestures in dialogue appear to function as a means of setting up and refining representational space for a narrative, one that supports the speaker infinitely more effectively than it could provide narrative enhancing illustrations for a listener. Gestures may have clear predicating meaning 
for a speaker - adjectival, adverbial, verbal, nominal - but are mostly such that no listener could hope to successfully decode the content of a discourse by watching without listening.

However, gestures do serve a communicative function with regard to psychological attitudes of speakers. Attending to gesture will give a watcher a reasonable set of cues about the emotions that the speaker has. One may speculate that this is why mainstream news broadcasters deploy seemingly stylized but simultaneously bizarre gestures while conveying reports on television. Perhaps this is a means of suppressing the revelation of their actual emotions towards the content they report.

\section{LINGUISTIC AND BEHAVIOURAL INTERACTION ANALYSIS}

Emotion, thought, language, and gesture, we argue, are coginfocom technologies. We attempt to discover basic facts about these technologies, how people adapt them and how their use interacts. Understanding linguistic and behavioural interactions is important to anticipating new technologies that may arise and extend human cognitive capabilities further. It seems that a pre-requisite for adoption of coginfocom innovations is that they have both private and public functionality, in the same manner that thought is a private primarily function and communication is a primarily public function: the successful proliferation of smart-phones may be attributed to the fact that they have assimilated functions of personal digital assistants and synchronous and asynchronous communication with individuals and groups. The problem solved by the innovation may not be the same in the private sphere and the public sphere, but the duality in spheres of use reinforces habituation.

Reasoning along the lines we suggest here might influence one's thinking about nascent coginfocom technology. Consider dialogue systems. Dialogue systems have been proposed and explored (including by us) for individuals in managing health and well-being. Dialogue systems primarily target private use. Increasingly, systems, online "bots", in particular have been introduced for public communication among many. Frequently, it seems that they have dubious ethical value in attempting to fool people into thinking that they are not bots, but people, and in attempting to spread disinformation widely. Dialogue systems appear to have clear private value but questionable public value. Therefore, one might reasonably project that dialogue system technology will not be assimilated by human culture. If public value (perhaps in gaming technology, particularly in a manner that facilitates players communicating with other human as well as other artificial players; or perhaps in the next generation of interactive cinema experiences) can be established for dialogue systems, as well, then a lasting future for dialogue systems might be projected.

Fidget spinners offer a solution to the problem of consuming nervous energy. This is a private function. They also had a public function shared with many other fads: namely, using one in public made one visible as someone who had access to a fidget spinner. Being a person who visibly has $\mathrm{X}$ is, in general, a limited public function, communicating little else beyond that. For most $\mathrm{X}$, public interest in having $\mathrm{X}$ is determined by how easy it is to have $\mathrm{X}$ and how long an $\mathrm{X}$ lasts. As more people have $\mathrm{X}$, more people want $\mathrm{X}$, up to a point, and then it is no longer differentiating to have $\mathrm{X}$, and therefore possessing $\mathrm{X}$ ceases to convey information. One can then expect interest in $X$ to wane. Returning to the specific case of fidget spinners, if they are released again in a manner that not just consumes energy but also harvests energy in a way that supports other activities in both private and public spheres, then one might imagine them re-capturing public interest.

Much research into coginfocom technologies validates those technologies in either private or public spheres. Naturally, this includes bench-marking the technologies with respect to prior art without directly seeking validation in private or public spheres, given that prior art may have had independent validation along those lines. For example, the role of many natural language technologies is clear within larger systems, therefore it makes sense to seek improvements on fundamental components like part of speech tagging or parsing. Similarly, it makes sense to explore fundamental properties of the public and private spheres themselves, in order to understand where problems in those areas exist. Given that these spheres are private and public with respect to humanity, and given the premise that cogninfocom is about extending the capabilities of humans, fundamental knowledge about humans behaving in public and private spheres is always a moving target, as new technologies are assimilated. Thus, within coginfocom, one expects to see research that seems to explore technology "for its own sake" and humanity "for its own sake", but which actually, if indirectly, contributes information about the viability of extending capabilities of both.

The discussion so far indicates that for coginfocom technologies to be assimilated as part of humanity, it is a necessary condition that they contribute solutions to problems in the private and public spheres. However, these are not sufficient conditions. A coginfocom technology may well provide useful solutions, while a "lesser" technology out-competes it. As an example, one might reflect again on the role of music. All but a few forms of music were proscribed from The Republic, because of the capacity of music to "excite the passions", thus diminishing control over the populace. It appears to be an implicit hypothesis that musical experiences impinge on mental states, and this hypothesis has empirical support [4]. Arguably, if the goal of communication were the revealing and sharing of mental states, one might develop music-based communication technology and anticipate a system that is more effective as a solution than natural language. ${ }^{6}$ Crucially, natural language affords the possibility of hiding mental states, through the potential it creates for ambiguity, vagueness, misrepresentation, partial truths and outright lies. On this line, the communicative value of language in the public sphere is precisely in its support of mis-communication. Music might provide a means of supporting thought and communication which is superior to that of natural languages, but natural languages have been more completely assimilated by humanity.

It is necessary for a coginfocom solution which becomes part of humanity to make contributions to both the private and public spheres. The category of the contributions may or may not be the same in both spheres, and further, it is open for the efficacy to be greater in one than the other. It is also open for other considerations to impinge where competing technologies address overlapping problems. While

\footnotetext{
${ }^{6}$ Prosody in natural language may be an example of a borrowing of this technology.
} 
some considerations such as determine the success of fads, as discussed above, may apply, it seems that in general, the "easier" solution wins. Ease may be judged in relation to computational efficiency/cognitive complexity or physical effort. To see that this is a non-trivial empirical hypothesis, it should be contrasted with an alternative criterion, for example, that, in general, the most "beautiful" solution wins. One might argue, again with reference to natural languages, that they are all of approximately equivalent computational complexity (context free or at most mildly context sensitive, and therefore at worst time polynomial in the length of the sentence to judge grammaticality) and therefore there is no choice to be made with reference to ease of use, even if there were universal perceptions that some particular language is more beautiful than the rest. Therefore, it makes sense that people, in general, continue to use their native language(s) unless changes in their circumstances place them in situations where other languages are useful to them. Others might make reference to smart telephones for an alternative argument that beauty presents criteria at least as powerful as "ease", particularly those who find the explanation of the market success of Apple Corporation's iPhones to be their beauty (and not the issues of exclusivity related to their monetary expense, as with other possible instantiations of $\mathrm{X}$, as discussed above).

As coginfocom technologies are assimilated, they create new problems and offer new affordances for adaptation. They interact with other aspects of humanity and open new questions about human behavior in isolation and within interactions.

\section{RELATED WORK}

We feel that the theory of successful coginfocom developments that we propose here is supported by work within coginfocom, its constituent disciplines and its cognate disciplines. Out understanding of coginfocom is consistent with accepted definitions [5], [6], [7] and syntheses of work in the area [8], [9]. Analysis of future advances human computer interaction has argued that understanding human limits, respecting them and overcoming them is integral to success [10], and interface "efficiency" is named as a criterian associated with success.

In the manner that we have addressed emotion, gesture, language and thought as coginfocom technologies, others have explored other representational systems humans have adopted for reasoning, in particular, maps, for spatial reasoning [11], [12]. Intersections are addressed as well, for example, language use in scenarios requiring communication about spatial directions [13], [14], [15]. Some have addressed linguistic representation of reasoning [16]. Inside the coginfocom community the dynamics of gesture in dialogue has been addressed [17], [18], [19], [20], [21], [22], as have emotion [23], the language of emotion [24], voice of emotion [25], [26], [27], image of emotion [28], [29], impacts of emotion on reasoning [30], and modality synthesis [31], [32], [33], [34], [35], [36], [37].

Naturally, outside the community of researchers who address contributing disciplines from the perspective of the assimilation into humanity of novel technologies, the constituent disciplines themselves, by definition, add to knowledge about the underlying phenomena. What coginfocom adds that is not typically explicit within traditional study of linguistics, for instance, is scrutiny of alternative (and additional) technologies that humans may adopt. ${ }^{7}$ We think that this is holds for each contributing discipline. Coginfocom adds to the contributing disciplines focus on each discipline's content as a technology that has, but might not have, been adopted by humans in the past or which might be adopted by humans in the near or distant future, and whose dynamics in isolation and interaction with other dimensions of humanity merit examination. One might wish to argue that an expanded view of cognitive science or of social psychology or of artificial intelligence or of any of the contributing disciplines would encompass coginfocom, and we would agree. A view of the contributing disciplines expanded to include the view that the content of that discipline involves a technology that has been assimilated into humanity but which is not essential to humanity would be equivalent. What we articulate here is a theory of successful coginfocom technology: for it to be assimilated, it must provide advantages in both the private and public spheres of human behaviour.

\section{CONCLUSION}

We have argued that viable coginfocom developments are those that operate both in the private and public spheres, enhancing human capabilities for thought and interaction. Coginfocom research may directly address both or constituent topics. Coginfocom research may seek to advance understanding of the interaction of these spheres or properties of the spheres themselves. We argue that research that extends and validates technologies or that attempts to understand the nature of human thought or communication, seemingly in isolation from direct questions of contribution to private and public spheres, still contributes useful information that advances coginfocom research. Therefore, we think that it is not incumbent on each contribution to present its relation to the whole of cognitive infocommunications. In fact, the relations may not be visible at the inception of the ideas nor after their validation in their own terms. Rather, we think it is of foremost importance that each contribution present new knowledge (which may even take the form of negative results) as completely as possible and with scholarly rigour: each must make privately acquired knowledge public. Others may then "connect the dots" in different ways, according to their own insights and inspirations.

\section{ACKNOWLEDGMENT}

This research is supported by the Science Foundation Ireland (grants 12/CE/I2267 and 13/RC/2106) through the CNGL programme and the ADAPT Centre.

\section{REFERENCES}

[1] A. Esposito, A. M. Esposito, and C. Vogel, "Needs and challenges in human computer interaction for processing social emotional information," Pattern Recognition Letters, vol. 66, pp. 41-51, 2015.

[2] M. O'Neill, “'Wholly Incommunicable by Words': Romantic expressions of the inexpressible," The Wordsworth Circle, vol. 31, no. 1, pp. 13-20, 1999

[3] D. MacNeill, "Growth points cross linguistically," in Language and Conceptualization, ser. Language, Culture \& Cognition, J. Nuyts and E. Pederson, Eds. Cambridge University Press, 1997, pp. 190-212.

[4] R. E. Milliman, "Using background music to affect the behavior of supermarket shoppers," Journal of Marketing, vol. 46, pp. 86-91, 1982.

\footnotetext{
${ }^{7}$ Of course, contemplation of alternatives to natural language is attested in linguistic theory (e.g. [38, Chr 2 (pp. 8-33), "The Peculiarities of Language"], but this is not the main activity of linguistic theory.
} 
[5] P. Baranyi and A. Csapo, "Definition and synergies of cognitive infocommunications," Acta Polytechnica Hungarica, vol. 9, no. 1, pp. $67-83,2012$.

[6] A. Csapo and P. Baranyi, "Coginfocom channels and related definitions revisited," in IEEE 10th Jubilee International Symposium on Intelligent Systems and Informatics (SISY), 2012, pp. 73-78.

[7] P. Baranyi, A. Csapo, and G. Sallai, Cognitive Infocommunications (CogInfoCom). Springer, 2015.

[8] G. Sallai, "The cradle of cognitive infocommunications," Acta Polytechnica Hungarica, vol. 9, no. 1, pp. 171-181, 2012.

[9] P. Baranyi, A. Csapo, and P. Varlaki, "An overview of research trends in CogInfoCom," in IEEE 18th International Conference on Intelligent Engineering Systems, ser. INES. IEEE, 2014, pp. 181-186.

[10] Á. Török, "From human-computer interaction to cognitive infocommunications: a cognitive science perspective," in 7th IEEE International Conference on Cognitive Infocommunications (CogInfoCom 2016), P. Baranyi et al., Eds. IEEE, 2016, pp. 433-438.

[11] Á. Török, Z. G. Török, and B. Tölgyesi, "Cluttered centres: interaction between eccentricity and clutter in attracting visual attention of readers of a 16th century map," in 8th IEEE International Conference on Cognitive Infocommunications (CogInfoCom 2017), P. Baranyi, A. Esposito, P. Földesi, and T. Mihálydeák, Eds. IEEE, 2017, pp. 433-437.

[12] Á. Török and Z. G. Török, "Looking at the map - or navigating in a virtual city: Interaction of visuospatial display and spatial strategies in vr," in 9th IEEE International Conference on Cognitive Infocommunications (CogInfoCom 2018), P. Baranyi et al., Eds. IEEE, 2018, pp. 327-333.

[13] J. Reverdy and C. Vogel, "Measuring synchrony in task-based dialogues," in Proceedings of the 18th Annual Conference of the International Speech Communication Association (INTERSPEECH2017). International Speech Communication Association, 2017, pp. 17011705, iSSN 2308-457X.

[14] C. Vogel, M. Ribeiro Lopes, and A. Esposito, "Gender differences in the language of the map task dialogues," in 8th IEEE International Conference on Cognitive Infocommunications (CogInfoCom 2017), P. Baranyi, A. Esposito, P. Földesi, and T. Mihálydeák, Eds. IEEE, 2017, pp. 151156.

[15] J. Reverdy, H. Akira, and C. Vogel, "Alignment in a multimodal interlingual computer-mediated map task corpus," in Proceedings of the Eleventh International Conference on Language Resources and Evaluation (LREC 2018), H. Koiso and P. Paggio, Eds. Paris, France: European Language Resources Association (ELRA), 2018, pp. 55-59.

[16] I. Poggi, F. D’Errico, and L. Vincze, "Uncertain words, uncertain texts. perception and effects of uncertainty in biomedical communication," Acta Polytechnia Hungarica, vol. 16, no. 2, pp. 13-34, 2019.

[17] A. Kendon, Gesture: Visible Action as Utterance. Cambridge University Press, 2004.

[18] A. Esposito and M. Marinaro, "What pauses can tell us about speech and gesture partnership," in The Fundamentals of Verbal and Non-Verbal Communication and the Biometrical Issue, A. Esposito, E. Keller, M. Marinaro, and M. Bratanic, Eds. Amsterdam: IOS Press, 2007, pp. $45-57$.

[19] C. Navarretta, "Alignment of communicative behaviors and familiarity in first encounters," in 2014 5th IEEE International Conference on Cognitive Infocommunications (CogInfoCom), 2016, pp. 185-190.

[20] — - "Predicting an individual's gestures from the interlocutor's cooccurring gestures and related speech," in 2016 7th IEEE International Conference on Cognitive Infocommunications (CogInfoCom), 2016, pp. 233-238.

[21] _ _ "Prediction of audience response from spoken sequences, speech pauses and co-speech gestures in humorous discourse by barack obama," in 2017 8th IEEE International Conference on Cognitive Infocommunications (CogInfoCom), 2016, pp. 327-332.

[22] M. Koutsombogera, R. Costello, and C. Vogel, "Quantifying dominance in the multisimo corpus," in 9th IEEE International Conference on Cognitive Infocommunications (CogInfoCom 2018), P. Baranyi, A. Esposito, P. Földesi, and T. Mihálydeák, Eds. IEEE, 2018, pp. 147-152.

[23] F. Berthelon and P. Sander, "On multimodality in the perception of emotions from materials of the hucomtech corpus," in 2013 th IEEE
International Conference on Cognitive Infocommunications (CogInfoCom), 2013, pp. 59-64.

[24] B. Lewandowska-Tomaszczyk and P. A. Wilson, "Compassion, empathy and sympathy expression features in affective robotics," in 2016 7th IEEE International Conference on Cognitive Infocommunications (CogInfoCom), 2016, pp. 65-70.

[25] A. Esposito, "The perceptual and cognitive role of visual and auditory channels in conveying emotional information," Cognitive Computation, vol. 1, no. 3, pp. 268-273, 2009.

[26] A. Esposito, M. T. Riviello, and N. Bourbakis, "Cultural specific effects on the recognition of basic emotions: A study on italian subjects," in HCI and Usability for e-Inclusion: 5th Symposium of the Workgroup Human-Computer Interaction and Usability Engineering of the Austrian Computer Society, USAB 2009, Linz, Austria, November 9-10, 2009 Proceedings, A. Holzinger and K. Miesenberger, Eds. Springer Berlin Heidelberg, 2009, pp. 135-148.

[27] A. Origlia, V. Galatá, and F. Cutugno, "Introducing context in syllable based emotion tracking," in 2014 5th IEEE International Conference on Cognitive Infocommunications (CogInfoCom), 2014, pp. 337-342.

[28] A. Esposito, A. M. Esposito, I. Cirillo, L. Panfilo, F. Scibelli, M. Maldonato, and C. Vogel, "Differences between hearing and deaf subjects in decoding foreign emotional faces," in 8th IEEE International Conference on Cognitive Infocommunications (CogInfoCom 2017), P. Baranyi, A. Esposito, P. Földesi, and T. Mihálydeák, Eds. IEEE, 2017, pp. 175180.

[29] A. Esposito, A. M. Esposito, G. Cordasco, M. Maldonato, C. Vogel, and N. Bourbakis, "Emotional faces of children and adults: What changes in their perception," in 9th IEEE International Conference on Cognitive Infocommunications (CogInfoCom 2018), P. Baranyi, A. Esposito, P. Földesi, and T. Mihálydeák, Eds. IEEE, 2018, pp. 105-110.

[30] O. Matarazzo, B. Pizzini, C. Greco, and M. Carpentieri, "Effects of a chance task outcome on the offers in the ultimatum game: The mediation role of emotions," in 7th IEEE International Conference on Cognitive Infocommunications (CogInfoCom 2016), P. Baranyi et al., Eds. IEEE, 2016, pp. 295-300.

[31] N. Bourbakis, A. Esposito, and D. Kvaraki, "Extracting and associating meta-features for understanding peoples emotional behaviour: Face and speech," Cognitive Computation, vol. 3, no. 3, pp. 436-448, 2011.

[32] A. Esposito, "The amount of information on emotional states conveyed by the verbal and nonverbal channels: Some perceptual data," in Progress in Nonlinear Speech Processing, ser. LNCS 4391, Y. Stylianou, M. Faundez-Zanuy, and A. Esposito, Eds. SpringerVerlag: Berlin, 2007, pp. 249-268.

[33] R. Volpe, L. Chanquoy, and A. Esposito, "The matrix of meaning: Representing meaning in mind; prolegomena to a theoretical mind," in Analysis of Verbal and Nonverbal Communication and Enactment: The Processing Issues, A. Esposito, A. Vinciarelli, K. Vicsi, C. Pelauchaud, and A. Nijholt, Eds. Heidelberg: Springer, 2011, pp. 48-55.

[34] M. T. Riviello, A. Esposito, and K. Vicsi, "A cross-cultural study on the perception of emotions: How Hungarian subjects evaluate American and Italian emotional expressions," in Cognitive Behavioural Systems, A. Esposito, A. M. Esposito, A. Vinciarelli, R. Hoffmann, and V. C. Müller, Eds. Springer, LNCS 7403, 2012, pp. 424-448.

[35] L. Hunyadi, "On multimodality in the perception of emotions from materials of the hucomtech corpus," in 2015 6th IEEE International Conference on Cognitive Infocommunications (CogInfoCom), 2015, pp. 489-492.

[36] S.-E. Fotinea, E. Efthimiou, M. Koutsombogera, A.-L. Dimou, T. Goulas, P. Maragos, and C. Tzafestas, "The mobot human-robot communication model," in 2015 6th IEEE International Conference on Cognitive Infocommunications (CogInfoCom), 2015, pp. 201-206.

[37] A. Esposito and L. C. Jain, "Modeling social signals and contexts in robotic socially believable behaving systems," in Toward Robotic Socially Believable Behaving Systems Volume II - Modeling Social Signals, A. Esposito and L. C. Jain, Eds. Springer International Publishing Switzerland, 2016, pp. 5-13.

[38] A. Carstairs-McCarthy, The Origins of Complex Language: An Inquiry into the Evolutionary Beginnings of Sentences, Syllables and Truth. Oxford: Oxford University Press, 1999. 